\title{
Visit to Cousin Island
}

\section{Tony Beamish}

A 70-acre granite island in the Seychelles with a remarkable bird population,* Cousin Island was bought last year for a wildlife reserve by the ICBP (International Council for Bird Preservation) and a warden installed. Tony Beamish, who has made an excellent film of the island's wildlife, describes some of the changes.

Cousin Island had been in the ownership of the ICBP for only nine months when I paid my second visit there in October and November 1968. Near the central hill the ghostly wailing of wedge-tailed shearwaters practically drowned the cackling and whistling of the fairy and noddy terns. For the first time in living memory the shearwaters were enjoying an unmolested nesting season. The warden, Philippe Lalanne, estimated 2,500 pairs in November and more were coming daily. Every year, until ICBP bought the island, the fat and greasy chicks had been cropped to provide a delicacy for Seychellois gourmets; several thousand chicks were spiked in their nest burrows for sale in Mahe. This season with nothing to fear except poachers, for which the resident staff were on the alert every night, a massive increase in the shearwater population was certain.

\section{Hawksbill Turtle}

Walking back along the beach that night I saw a dark hump lurching above the high tide mark. At first I thought it was one of the giant tortoises of Cousin, possibly the last survivors of the Seychelles stock, but it proved to be a hawksbill turtle. These creatures are everywhere hunted for their shell-unlike the green turtle they are not good to eat - so it was encouraging to find no fewer than three nests already marked and protected. Cousin Island could well become a breeding base from which these and other turtles might re-populate the shallow seas around the central group.

There had been no time for any visible increase in the numbers of the unique brush warbler Nesillas seychellensis since ICBP took over, but I was delighted to find nests at five different places on the plateau. From one unusually low nest at just over three feet we were able to describe the warbler's egg, possibly for the first time. In all the nests there was only a single egg, but it is possible that there are two breeding seasons in the year. One had a nearly full fledged chick which filled the tiny cup.

There is no doubt that the bird population of Cousin is growing, and the future prospects look exciting. To me the most encouraging sign of all was the growing interest and even pride of local people in the tiny island, the consequence of the international interest shown in it. The ICBP is appealing for $£ 50,000$ to buy and maintain the island as a reserve, and build and equip a research station. Gifts may be sent to the FPS to be forwarded.

* Described in Oryx, December 1967. 